\title{
Adaptation of Local Rabies Virus Isolates to High Growth Titer and Determination of Pathogenicity to Develop Canine Vaccine in Ethiopia
}

Abebe Mengesha Aga*, Birhanu Hurisa, Tihitina Tesfaye, Hailu Lemma, Dereje Niguse, Gashaw G/Wold, Amha Kebede, Tsehaynesh Mesele and Kelbessa Urga

Ethiopian Public Health Institute, Addis Ababa, Ethiopia

"Corresponding author: Abebe Mengesha, Ethiopian Public Health Institute, Addis Ababa, Ethiopia, E-mail: agagurmu@yahoo.com

Received date: Apr 30, 2014, Accepted date: Aug 17, 2014, published date: Aug 24, 2014

Copyright: (C) 2014 Aga, et al. This is an open-access article distributed under the terms of the Creative Commons Attribution License, which permits unrestricted use, distribution, and reproduction in any medium, provided the original author and source are credited.

\begin{abstract}
Rabies is a zoonotic viral disease which causes acute encephalitis in humans and animals. The case is most severe in developing countries where cell culture derived anti-rabies vaccines are unaffordable or the available nervous tissue-derived vaccines are of questionable immunogenicity and may cause neurological complications. The aim of this research was to adapt local rabies virus isolates on BHK-21 and to study pathogenicity to intramuscular route of inoculation for canine vaccine development. The viruses were isolated from rabid dogs' brain and human saliva, and adapted to Swiss albino mice brain and cell lines by several blind passages. By titration, a minimum of $10^{6.5} \mathrm{TCID}_{50} / \mathrm{ml}$ (in vitro) and $10^{4.5} \mathrm{MICLD}_{50} / 0.03 \mathrm{ml}$ (in vivo) virus titer were obtained. For pathogenicity study, mice were inoculated intramuscularly with $250 \mathrm{MICLD}_{50} / 0.1 \mathrm{ml}$ of each adapted virus isolate and observed for 45 days. Only two virus isolates, human origin sululta (HOS) and dog origin (DO) caused $12.5 \%$ death. This can show the phylogroup origin of the viruses indicating phylogroup I origin of these virus isolates with decline in virulence. Decline in pathogenicity may be due to adaptation of the viruses to mice brain and cell lines to increase virus infectivity titer. Generally, the exact genetic relationship with fixed rabies virus strain should be studied by molecular techniques and canine anti-rabies vaccine develops from locally isolated viruses.
\end{abstract}

Keywords: Adaptation; Cell culture vaccine; Local isolates; Pathogenicity

\section{Introduction}

Rabies is a zoonotic viral disease which causes acute encephalitis in humans and animals. The disease affects domestic and wild animals, and spread to humans through close contact with infectious material, usually saliva, via bites or scratches. In developing countries, with limited access to high-quality anti-rabies biologics, approximately 55,000 people and millions of animals die every year due to rabie [1]. Almost all human rabies is caused by the bite of a rabid animal. The risk of rabies is highest in countries with hyper-endemic canine rabies, including most of Asia, Africa, and Latin America [2].

Rabies is one of the most severe infectious diseases in Ethiopia, with many cases of the disease diagnosed in various parts of the country [3]. Most of the cases are due to bite by stray dogs. The dog is the species most responsible for human exposure, with over $94.01 \%$ of the total positive animals [4]. As a result, vaccination of domestic animals (mostly dogs) and wildlife (mostly foxes) is the only way of reducing or elimination of rabies [5]. In Ethiopia, brain samples collected from domestic animals, two rabies-related viruses were isolated [6]. According to their reactivity pattern with anti-nucleocapsid monoclonal antibodies, they were characterized as Lagos bat virus and Mokola virus. But, little is known about the biological characteristics of these isolates and about the ability of current rabies vaccines to elicit immune responses which would provide cross-protection.

There are two types of anti-rabies vaccines; the nerve tissue-based vaccine and the non-nerve tissue vaccine. The currently available nonnerve tissue vaccines are Purified Chick Embryo Cell (PCEC) vaccine, Human Diploid Cell Vaccine (HDCV), Purified Vero Cell Vaccine
(PVRV) and Purified Duck Embryo Vaccine (PDEV). Similarly, there are two types of rabies virus strains; the fixed type of rabies virus which is used for vaccine production and the wild type virus which is street rabies virus strain.

Illness due to rabies can be prevented by administering anti-rabies antibodies and a series of vaccination, provided exposure is recognized before the symptoms appear. Closely related lyssaviruses circulate among bats, and can cause an illness identical to rabies in human and domesticated animals [7]. Rabies virus and the rabies-related lyssaviruses have been classified into two or more phylogroups, based on their genetic relatedness. Rabies vaccines and post-exposure prophylaxis are thought to provide protection against some of these viruses (Phylogroup I), but not for some of phylogroup II species [8]. Rabies-related lyssaviruses can be found even in countries classified as rabies-free. The virus has a non-segmented and negative-stranded RNA genome with about 12,000 nucleotides. Lagos bat virus, Duvenhage virus, European bat lyssavirus (EBLV) 1, EBLV 2, Australian bat lyssavirus (ABLV), Mokola virus and Irkut virus have caused clinical cases in humans or domesticated animals [7]. Phylogroup I contains rabies virus, Duvenhage virus, EBLV 1, EBLV 2 and Australian bat lyssavirus, and Phylogroup II consists of Lagos bat virus, Mokola virus and Shimoni bat virus [9]. Viruses that are more closely related to rabies virus can be neutralized, at least to some extent, by antibodies to rabies virus [9]. Viruses that are far from rabies virus in their glycoprotein genetic makeup cannot be neutralized by antibody raised to classical rabies virus and can affect efficacy of the vaccine [9-13]. 
Page 2 of 4

\section{Materials and methods}

\section{Laboratory animals}

Swiss albino mice were used for clinical virus isolation, blind passage and in vivo virus titer determination. Mice, 3-4 weeks old, weighing 6-8 grams with identical sex were used. Mice were obtained from Ethiopian Public Health Institute (EPHI), Laboratory Animal Breading Center.

\section{Cell lines}

A Baby Hamster Kidney (BHK-21) cell line purchased from American Type Culture Collection (ATCC) was used for virus adaptation and in vitro titer determinations.

\section{Virus used}

Local rabies viruses were collected from rabid animal brain and human saliva. Four local virus isolates; two from human saliva (human origin Wollega (HOW) and human origin Sululta (HOS)), one from rabid dog brain (dog origin (DO) from Gojjam) and one from rabid cow brain (cow origin (CO) from Butajira) were used. The location of the virus isolate represents different state of Ethiopia to check the difference due to locations (Table 1).

\begin{tabular}{|l|l|l|l|}
\hline $\begin{array}{l}\text { Type } \\
\text { Virus }\end{array}$ & Origin & Location & Remarks \\
\hline HOW & Human Saliva & Wollega & Mice inoculation positive \\
\hline HOS & Human saliva & Sululta & Mice inoculation positive \\
\hline DO & Dog brain & Gojam & FAT positive \\
\hline CO & Cow brain & Butajira & FAT positive \\
\hline PV-12 & Cow brain & $\begin{array}{l}\text { France, } \\
\text { Paris }\end{array}$ & $\begin{array}{l}\text { Currently used for Fermi vaccine } \\
\text { production in the country }\end{array}$ \\
\hline
\end{tabular}

\section{Fluorescent antibody test}

After collection of the samples, FAT test was done to confirm the presence of viruses. Fluorescent Isothiocyanet (FITC) labelled monoclonal antibodies originated from Russia were used in FAT and titration test. For saliva samples, intracerebral mice inoculation test was used to propagate virus on mice brain. In FAT test, brain sample was applied on slide and fixed with acetone at $-20^{\circ} \mathrm{C}$ for 5 minute. After the acetone dried out, samples were covered with anti-rabies antibody and incubated at $37^{\circ} \mathrm{C}$ for $30 \mathrm{~min}$. Slides were rinsed with PBS twice and examined under 40X objective fluorescent microscopes. This test was used throughout the experiment to confirm collected samples and to identify specific and non-specific death of mice inoculated with the rabies virus during the experiment.

\section{Isolation of the samples}

All positive brain samples were homogenized and prepared as $10 \%$ weight by volume ( $\mathrm{w} / \mathrm{v})$ brain suspension. Homogenization was done by suspending the sample phosphate buffered saline (PBS), stored at $-80 \mathrm{oC}$ for $1-2 \mathrm{hrs}$ with shaking vigorously. Brain suspensions were centrifuged at $3,000 \mathrm{xg}$ under refrigeration for $10 \mathrm{~min}$. The supernatant fluid containing rabies virus was used as original inoculum (without dilution), for mice inoculation after purification by filtration with filter pore size $0.22 \mu \mathrm{m}$.

\section{Virus adaptation}

To adapt the local virus isolates to cell lines, it is required to adapt first to mice brain to increase infectivity titer. The virus was adapted to mice brain by passaging five times on mice brain without finding virus titer. After five passages, the last brain samples were homogenized in $10 \% \mathrm{w} / \mathrm{v}$ PBS, and purified by centrifugation (at 3,000xg) and filtration with $0.22 \mu \mathrm{m}$ sterile filter. BHK-21 cell lines were cultured in $75 \mathrm{~cm}^{2}$ tissue culture flask using Eagle Minimum Essential Medium (EMEM) supplemented with $10 \%$ fetal bovine serum. After 72 hours, when monolayer (cell confluence) was reached, cells were trypsinized. The cell concentration was determined and inoculated with brain supernatant at 0.1 virus/cells. Infected cells were incubated at $37^{\circ} \mathrm{C}$ for 30 minutes with mixing every 5 minutes. After 30 minutes, cells were centrifuged at $2500 \mathrm{rpm}$ for 10 minutes, supernatant removed and cell pellet re-suspended in $5 \mathrm{ml}$ complete medium (contain $10 \%$ fetal bovine serum, 3.5\% $\mathrm{NaHCO}_{3}$ and $1 \%$ L-glutamine). The cell suspensions were transferred to $25 \mathrm{~cm}^{2}$ tissue culture flasks and incubated for 72 hours at $37^{\circ} \mathrm{C}$ in a humid incubator with $5 \% \mathrm{CO}_{2}$. Viruses were passaged twenty times on cell lines with titration every five passage. At each passage, tissue culture supernatant (TCSN) were harvested, aliquoted, and stored at $-80^{\circ} \mathrm{C}$.

Titration of the virus was used to determine growth and multiplicity infection of the rabies virus during passage on mice brain and cell lines. A serial tenfold dilution of the virus was prepared in incomplete media (media without fetal bovine serum) and distributed on 96 well micro-titration plates. Concentration of BHK-21 cell lines adjusted to $6 \times 10^{5}$ cells $/ \mathrm{ml}$ and $30 \mu \mathrm{l} /$ well was added to each well. After 48 hours of incubation period at $37^{\circ} \mathrm{C}$ with $5 \% \mathrm{CO}_{2}$, plates were stained with antirabies conjugate and reading was done under fluorescent microscope. Based on the positive/negative readings, titer of the virus was calculated using Spearman Kärber formula. This was expressed as tissue culture infectivity dose per milliliter $\left(\mathrm{TCID}_{50} / \mathrm{ml}\right)$ of virus titer. In addition, titration of the virus was done on mice brain after twenty passages on cell lines. Tenfold serial dilution of original cell lines adapted viral suspension was prepared up to $10^{-8}$ using PBS as diluents. A group of eight mice were inoculated with $0.03 \mathrm{ml}$ of each virus dilution intracerebrally. Mice were observed for 14 days and death and survival rate recorded separately. Based on the number of specific deaths, mice intracerebral lethal doses $\left(\mathrm{MICLD}_{50} / 0.03\right)$ were calculated using Spearman Kärber formula.

$$
\begin{aligned}
& \log 10 \text { (end-point dilution })=\left(\mathrm{x}_{0}-\frac{\mathrm{d}}{2}+\mathrm{d} \sum \frac{\mathrm{r}_{\mathrm{i}}}{\mathrm{n}_{\mathrm{i}}}\right) \\
& \text { where } \\
& \mathrm{x} 0=(\log 10 \text { of the lowest dilution with all wells positive) } \\
& \mathrm{d}=\log 10 \text { of the dilution step, one in this case } \\
& \mathrm{ni}=\text { number of replicates } \\
& \mathrm{ri}=\text { number of positive wells. }
\end{aligned}
$$

\section{Determination of pathogenicity}

After five passage on mice brain and twenty passages of local rabies virus isolates on cell lines, the mice intracerebral lethal dose viral titer was determined. In pathogenicity test, one group of mice $(n=16)$, were injected through intramuscular (IM) route on the thigh with $0.1 \mathrm{~mL}$ $\left(250 \mathrm{MICLD}_{50} / 0.1 \mathrm{~mL}\right)$ of each virus isolates. Control mice were 
Page 3 of 4

injected with PBS. All test and control groups of mice were observed for 45 days. Brain of mice died during the incubation period was removed and FAT was performed to confirm the presence of rabies virus.

\section{Results}

\section{Virus adaptation results}

In each blind passage, the virus shows different multiplicity of infection by in vitro titration methods at each blind passage. A oneway analysis of variance was conducted to test if there were difference in virus titer among blind passages. According to these results, the rabies viruses showed increase infectivity titer throughout the passage. Adaptation of the virus expressed as a titer and the result of titration both in vivo and in vitro methods was performed (Figure 1). There was significant difference in growth of virus titer between each blind passage for each viruses, $\mathrm{F}(1,4467)=2528.9, \mathrm{p}=0.000$. But, no significant difference in infectivity titer between viruses at each blind passage, $\mathrm{F}(1,4467)=0.697, \mathrm{p}=0.451$.

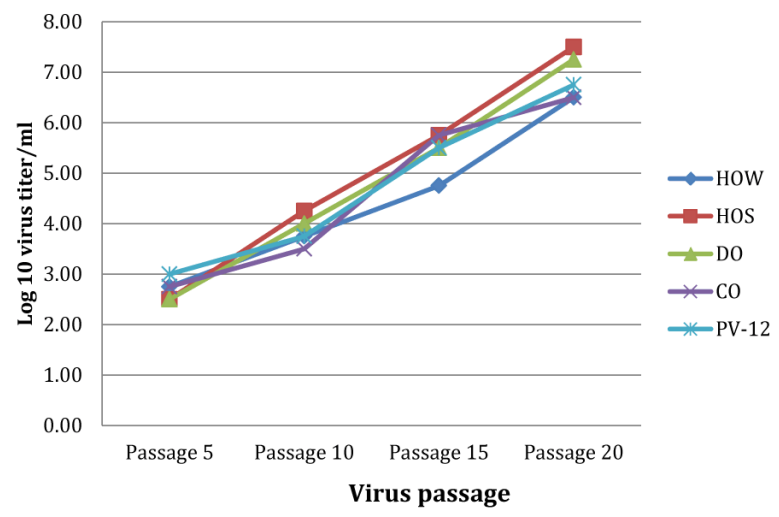

Figure 1: In vitro virus titer result at each five blind passages up to twenty passages on BHK-21 cell lines which can be used for further cross neutralization and pathogenicity test.

According to this result, the titer of the virus increased throughout the blind passages reaching maximum and minimum of virus titer $10^{7.5} / \mathrm{ml}$ (HOS) and $10^{6.5} / \mathrm{ml}$ (HOW and CO) in terms of tissue culture infectivity dose per milliliter. Similar study done by Guo et al support the idea of increase in virus titer through passage but after pick point $\left(10^{7.9} \mathrm{FFU} / \mathrm{ml}\right)$, the titer start to drop (Guo et al., 2014). In vivo method of titer determination was also done on Swiss albino mice brain after twenty passages on cell lines (Table 2).

According to the result, maximum and minimum of $10^{5.9} / 0.03 \mathrm{ml}$ (HOS) and $10^{4.5} / 0.03 \mathrm{ml}$ (HOW and CO) mice intracerebral lethal dose $\left(M_{\text {ICLD }}\right)$ were obtained (Table 2$)$. These results were used to determine working dilution of the specific virus according to its titer for pathogenicity study.

\section{Pathogenicity test}

The pathogenicity of local virus isolate was evaluated after five passages on mice brain and twenty passages on BHK-21 cell lines. According to the results obtained, all virus isolates almost lost their virulence to intramuscular inoculation except two virus isolates (HOS and DO) that killed two mice related to rabies virus out of 16 inoculated mice (Table 3 ).

\begin{tabular}{|l|l|}
\hline Virus origin & MICLD ${ }_{50} / 0.03 \mathrm{ml}\left(\mathrm{P}_{20}\right)$ \\
\hline HOW & $10^{4.5}$ \\
\hline HOS & $10^{5.9}$ \\
\hline DO & $10^{5.5}$ \\
\hline CO & $10^{4.5}$ \\
\hline PV-12 & $10^{5.25}$ \\
\hline
\end{tabular}

\begin{tabular}{|l|l|l|}
\hline Type of virus & \% Death & \% Survival \\
\hline HOW & 0 & 100 \\
\hline HOS & 12.5 & 87.5 \\
\hline DO & 12.5 & 87.5 \\
\hline CO & 0 & 100 \\
\hline
\end{tabular}

Table 3: Pathogenicity test result.

Fisher's exact test was used to determine statistical significance difference in pathogenicity and $\mathrm{P}<0.05$ were obtained. According to this result, there is no statistical significant difference between death and survival for the two viruses (HOS and DO). This shows that only $12.5 \%$ death occurred from inoculated mice which may indicate the decline of pathogenicity of the virus for IM route of inoculation. The other two viruses (HOW and $\mathrm{CO}$ ) have no pathogenicity at all indicating total decline in pathogenicity after adaptation.

\section{Discussion and Conclusion}

This study was designed to adapt local rabies virus isolate to high titer in cell culture and mice brain. All virus isolates grew well and showed increase in infectivity titer throughout the passages reaching a minimum titer of $10^{6.5} \mathrm{TCID}_{50} / \mathrm{ml}$ and $10^{4.5} \mathrm{MICLD}_{50} / \mathrm{ml}$ in vitro and in vivo virus titer, respectively. These virus titers reflect the adaptation nature of the virus to both mice brain and cell lines after several passages. According to $\mathrm{WHO}$ recommendation, the virus titer should be greater than or equal to $10^{6} \mathrm{TCID}{ }_{50} / \mathrm{ml}$ and fixed in its growth titer to be used for as vaccinal strain (WHO, 2005). The titers of the viruses were high and can be used for further study. The titer and its pathogenicity to IM route of inoculation can be further improved by passaging on cell lines and mice brain to obtain the pick virus titer.

Pathogenicity test reveal decline in pathogenicity to IM route of inoculation after adaptation to mice brain and cell lines. Only HOS and DO show some pathogenicity (12.5\%) which can show phylogroup I origin of these viruses. Decline in pathogenicity may be due to adaptation of the virus to cell lines and mice brain which account for G-protein expression. Studies done in China also support that virulence of rabies virus declined with change in adaptation of the virus to chick embryo cells. The rest of the virus isolates (HOW and CO) have no pathogenicity at these numbers of passages. The study done in South Africa confirmed that inoculation with $10 \%$ suspension of the original brain material resulted in an increase in percentage mortality and a decrease in mean incubation period compared to 
Citation: Mengesha A, Hurisa B, Tesfaye T, Lemma H, Nigus D, et al. (2014) Adaptation of Local Rabies Virus Isolates to High Growth Titer and Determination of Pathogenicity to Develop Canine Vaccine in Ethiopia. J Vaccines Vaccin 5: 245. doi:10.4172/2157-7560.1000245

Page 4 of 4

inoculation with a dose of $10^{5} \mathrm{TCID}_{50}$ (Kgaladi et al., 2013). Several passages affect the pathogenicity of the virus on IM route of inoculation resulting only pathogenic to cell lines and intracerebral route of inoculation. In studies done by Koraka and his colleague, pathogenicity of lyssaviruses known to be invasive when isolated from wild and inoculated on mice before adaptation by several passages to cell lines and mice brains (Koraka et al., 2012). Therefore, decline in pathogenicity of the virus to intramuscular route of inoculation may indicate that the viruses have adapted to grow on mice brain and cell lines. Therefore, this test determines pathogenicity through IM route of inoculation after several passages of the virus to assess decline in virulence. The failure may arise due to genetic difference between local virus isolates and fixed vaccinal strain can be overcome by developing vaccinal strain from locally circulating virus. From the four local rabies virus isolates, strain with high titer and cross protection will be selected for canine vaccine production locally. Additional study should be conducted to determine genetic relationship between vaccinal strain and local isolates. To determine the exact genetic difference, molecular techniques should be used which can differentiate phylogroup origin of the viruses. Finally, this study helps to develop vaccine from these locally isolated viruses for mass vaccination of host animals to prevent and control the disease.

\section{References}

1. WHO (2005) World Health Organisation, WHO Technical Report Series, 931, WHO, Geneva. 1-87.

2. Lembo T, Niezgoda M, Velasco-Villa A, Cleaveland S, Ernest E, et al. (2006) Evaluation of a direct, rapid immunohistochemical test for rabies diagnosis. Emerg Infect Dis 12: 310-313.
3. Fekadu M (1982) Rabies in Ethiopia. Am J Epidemiol 115: 266-273.

4. Tefera G, Yimer E, Geyid A (2002) Endemic existence of rabies in Ethiopia. Ethiop Med J 40: 163-170.

5. Bethelihem Newayeselassie, Eshetu Yimer, Peteros Abebe, Abebe Bekele, Badeg Zewdie et al. (2004) Occurrence of rabies in humans and animals in Addis Ababa in 2001-2002. Ethiop. J Biol Sci 3: 59-67.

6. Mebatsion T, Cox JH, Frost JW (1992) Isolation and characterization of 115 street rabies virus isolates from Ethiopia by using monoclonal antibodies: identification of 2 isolates as Mokola and Lagos bat viruses. J Infect Dis 166: 972-977.

7. Smith AL, Tignor GH, Emmons RW, Woodie JD (1978) Isolation of field rabies virus strains in CER and murine neuroblastoma cell cultures. Intervirology 9: 359-361.

8. Badrane H, Bahloul C, Perrin P, Tordo N (2001) Evidence of two Lyssavirus phylogroups with distinct pathogenicity and immunogenicity. J Virol 75: 3268-3276.

9. Leslie MJ, Messenger S, Rohde RE, Smith J, Cheshier R, et al. (2006) Batassociated rabies virus in Skunks. Emerg Infect Dis 12: 1274-1277.

10. Sacramento D, Badrane H, Bourhy H, Tordo N (1992) Molecular epidemiology of rabies virus in France: comparison with vaccine strains. J Gen Virol 73: 1149-1158.

11. Koraka P, Martina BE, Roose JM, van Thiel PP, van Amerongen G, et al. (2012) In vitro and in vivo isolation and characterization of Duvenhage virus. PLoS Pathog 8: e1002682.

12. Kgaladi J, Nel LH, Markotter W (2013) Comparison of pathogenic domains of rabies and African rabies-related lyssaviruses and pathogenicity observed in mice. Onderstepoort J Vet Res 80: 511.

13. Guo C, Wang C, Luo S, Zhu S, Li H, (2014). The adaptation of a CTN-1 rabies virus strain to high-titer growth in chick embryo cells for vaccine development. Virol J 11: 85. 